\title{
Solar power sharing between two PV systems in a solar pyramid micro-grid
}

\author{
Po-Chien Hsu ${ }^{a}$, Bin-Juine Huang ${ }^{\text {a* }}$, Yi-Hung Wang ${ }^{\text {a }}$, Tzu-Chiao Tang ${ }^{\text {a }}$, Jia-Wei \\ Wang ${ }^{\mathrm{a}}$, Xin-Hong Dong ${ }^{\mathrm{a}}$, Kang $\mathrm{Li}^{\mathrm{a}}$, Kung-Yen Lee ${ }^{\mathrm{b}}$ \\ ${ }^{a}$ Department of Mechanical Engineering, National Taiwan University, Taipei, Taiwan \\ ${ }^{b}$ Department of Engineering Science and Ocean Engineering, National Taiwan University, Taipei, Taiwan
}

\begin{abstract}
The hybrid PV system (HyPV) is a solar PV system for self-consumption which operates at stand-alone PV mode or grid mode automatically and does not feed access PV power into grid. HyPV operates at PV mode when solar radiation or battery energy is high enough. It switches to grid mode when battery storage is low. There may be a PV generation loss if the system match between load and sizes of battery and PV modules is not proper. We proposed a networking technique, called "solar pyramid micro-grid", which connects neighbor HyPVs, and shares solar PV power each other. The binary connection of HyPVs is the simplest design to build a solar pyramid micro-grid. Solar PV power generation of HyPVs can be shared each other through a switching control. In the present study, the binary connection of two HyPV systems at A-level (called "Hynet-2A") was built and tested. The test results show that the sharing of access solar PV power each other can effectively increase the PV power generation of the whole micro-grid system. The longterm solar PV energy generation of Hynet-2A is close to that of grid-tied solar PV systems.
\end{abstract}

Keywords: Solar micro-grid; solar PV; solar PV for self-consumption.

\section{Introduction}

Most grid-tied solar PV systems installed today feeds all the PV power into the grid, due to feed-intariff (FIT) policy. If solar PV is in high-penetration ratio, the solar power feed-in will cause grid instability.

Harry Wirth [1] pointed out that an equal distribution of PV installations across all of the grid sections is necessary for high penetration of solar PV. Pudjianto et al [2] found from a study that moving PV installation beyond 10 percent of national total electricity supply will be difficult for countries with conditions like those in northern Europe, where power demand is relatively low in the summer. The study finds that Greece could get around 18 percent of its electricity from photovoltaics because demand coincides with solar power supply. But for Germany to go beyond 10 percent, storage will be needed.

It is obvious that there is a limit in national solar PV penetration if all relies on feed-in solar PV system. Hence, solar PV for self-consumption and with storage will be very important in high penetration of solar energy.

Many solar PV hybrid systems with battery storage for self-consumption were proposed, for example in [3]-[5]. Following the similar concept of [3]-[5], a typical solar hybrid system (microgrid) as shown in Fig. 1 was built in Taiwan [6]. This hybrid system includes $78 \mathrm{kWp}$ solar PV, $9.8 \mathrm{~kW}$ wind power, 159 $\mathrm{kWh}$ Li-battery, and $60 \mathrm{~kW}$ diesel power generator. Solar power does not feed into grid. The battery can be charged by solar, wind, diesel, or grid power. Three magnetic contactors (MC1, MC2, MC3) are used to switch the system into different operating modes. Three large power electronic controllers, MPPT/ inverter, charger, and load inverter, are used and may cause energy losses and reliability problems [7].

\footnotetext{
*Manuscript received October 20, 2016; revised April 10, 2017.

Corresponding author: Bin-Juine Huang. Tel.: +886 918291621; E-mail address: bjhuang@ seed.net.tw.

doi: $10.12720 /$ sgce.6.2.96-103
} 
This solar hybrid system is quite complicated and costly.

National Taiwan University have developed a simple solar hybrid system, called "hybrid solar PV system (HyPV)" which is in a simple structure as shown in Fig. 2 [8].

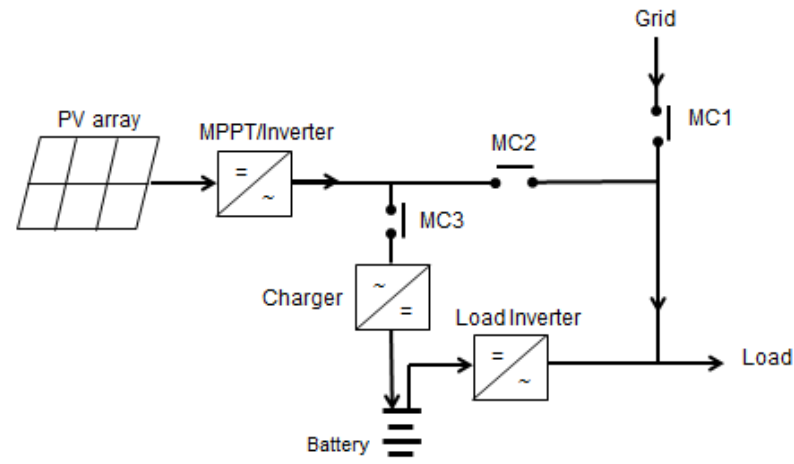

Fig. 1. Conventional solar micro-grid.

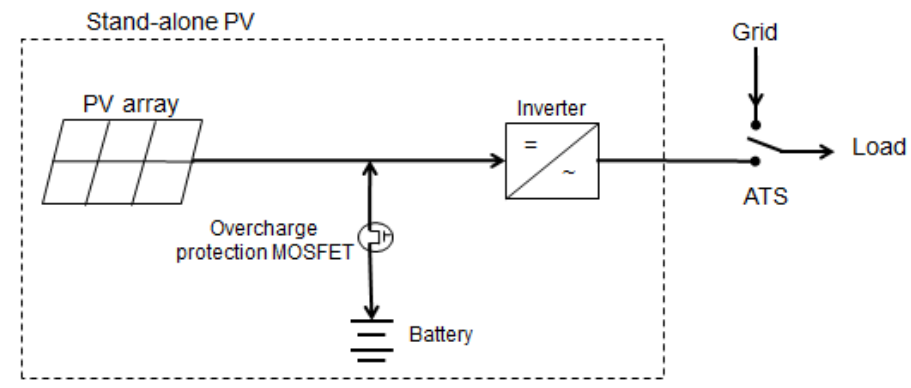

Fig. 2. Hybrid PV system (HyPV).

HyPV does not use MPPT (maximum-power-point tracking controller) and regular battery charger. HyPV operates at stand-alone PV mode or grid mode automatically and does not feed power into grid. HyPV operates at PV mode when solar PV power generation or battery storage is high enough. It switches to grid mode when battery storage is low. The switch scheme from grid to PV mode determines the system performance, including life of battery and switching device, and PV energy generation loss. This has been extensively studied and the results are published in [8]. HyPV is a solar PV power system for self-consumption without feeding PV power into grid. There may be a PV generation loss if the system match between load and sizes of battery and PV modules is not very well. To cope with this problem, we proposed a networking technique, called "solar pyramid micro-grid", which connects neighbor HyPVs and shares solar PV power each other through a switching control. Solar pyramid microgrid constructed based on binary connection of HYPVs at 3 levels is shown in Fig. 3. In this size of solar pyramid micro-grid, solar PV power of eight HyPVs can be shared each other through a smart control. The binary connection of HYPVs is the simplest design to build a solar pyramid micro-grid.

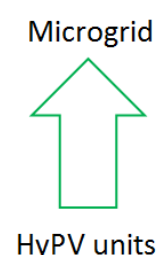

HyPV units
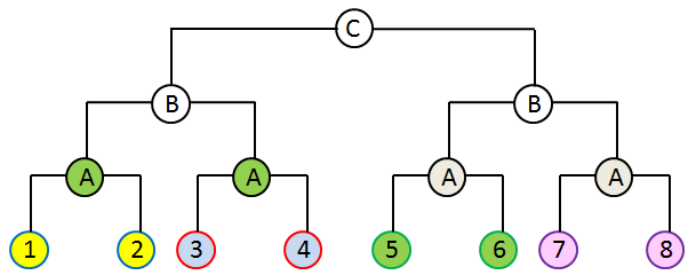

Fig. 3. Solar pyramid micro-grid based on binary connections. 
In the present study, two HyPV systems connected at A-level, called "Hynet-2A", was built and tested.

\section{Solar Micro-Grid Constructed from Binary Connection of HYPV Systems}

The individual HyPVs can be connected in a binary structure (A-level) in order to share the solar PV power each other when one of the HyPVs is at low load and its battery storage is full. Two pairs of HyPVs can be further connected in binary form as B-level for 4 individual HyPVs to share excess solar power each other. See Fig.4. The central control unit (CCU) for connection of each pair of HyPV (A1level) is shown in Fig. 5. The CCU of B1 is the same as A1 in hardware, but with different control logic. The connection is at the ac output of the DC/DC inverter of HyPV. Access solar PV power in one HyPV with battery full will be shared by the other HyPVs through A1, A2 or B1 switching.

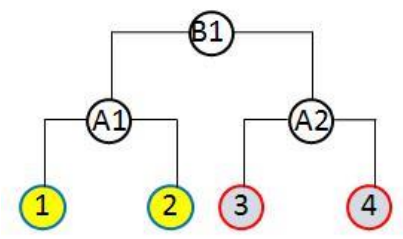

Fig. 4. Binary connection of individual HyPVs.

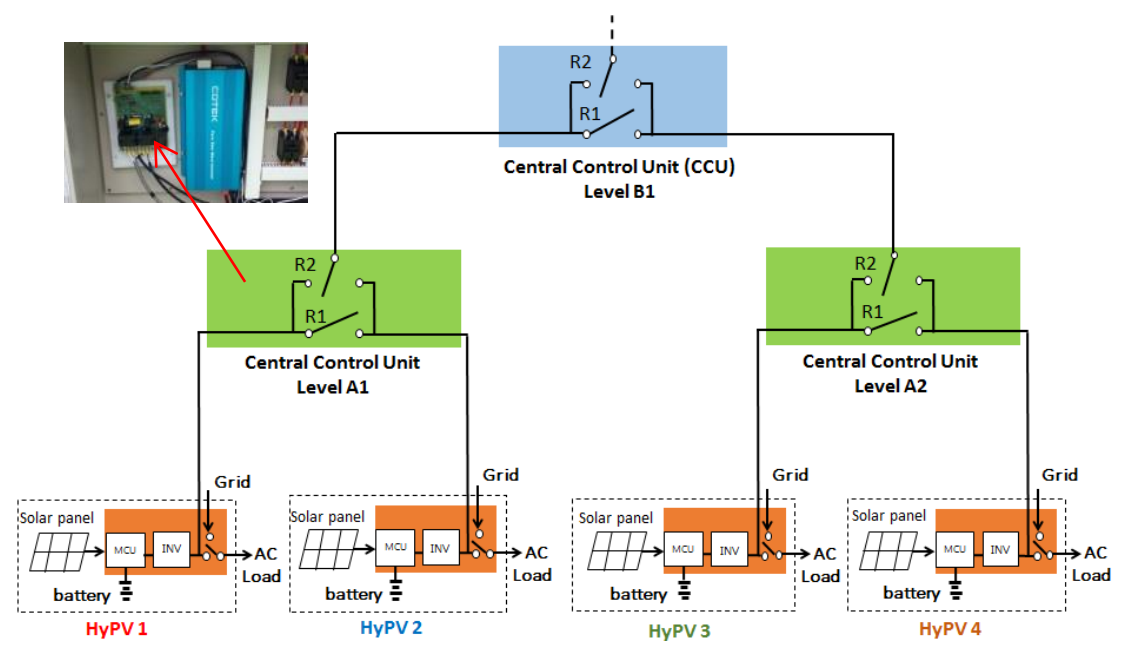

Fig. 5. B-level binary connections of HyPVs.

\section{Experimental Study of Two HyPVs Connected at A-level}

\subsection{Design of two HyPVs with A-level connection (Hynet-2A)}

The A-level system with two individual HyPVs is the basic unit of the solar pyramid micro-grid, called "Hynet-2A", and was built for field test to study the PV power sharing between neighbour HyPVs. Two HyPVs (D0 and D2) are selected for the binary connection, with different design of HyPV and load. Table 1 summarizes the design of the two HyPVs, D0 and D2.

HyPV-D0 consists of a $1.38 \mathrm{kWp}$ solar PV module which was designed and installed in a low-energy house (ZEH-2, Fig. 6) to drive a split inverter-type air conditioner (Hitachi RAS-22NB) and LED lighting. The estimated solar PV energy generation is $3.4 \mathrm{kWh}$ per day and the load demand is around $6 \sim 8 \mathrm{kWh}$ per day, mostly in daytime. ZEH-2 is not used every day if there is no meeting.

The inside dimension of ZEH-2 is $7.4 \mathrm{~m}$ long, $3.8 \mathrm{~m}$ wide, $3 \mathrm{~m}$ high with floor area $28 \mathrm{~m}^{2}$. This house is used as a meeting room for 12 persons. The overall $\mathrm{U}$-value is $0.22 \mathrm{Wm}^{-2} \mathrm{~K}^{-1}$. The total cooling load of ZEH-2 is estimated 2,200W in summer supplied by the inverter-type air conditioner with power 
consumption 100 700W at COP around 5.7.

A $220 \mathrm{~V} / 1.5 \mathrm{~kW}$ inverter was used in D0 to convert the dc power into ac to drive the air conditioner. The cooling load as well as the power consumption of air conditioner varies with ambient condition.

Table 1. System design specification of HyPV-D0 and D2.

\begin{tabular}{|c|c|c|}
\hline & HyPV-D0 & HyPV-D2 \\
\hline \multicolumn{3}{|l|}{ Solar PV system: } \\
\hline Capacity of solar PV module & $1,380 \mathrm{Wp}$ & $490 \mathrm{Wp}$ \\
\hline Average PV energy generation & $3.4 \mathrm{kWh} /$ day & $1.2 \mathrm{kWh} / \mathrm{day}$ \\
\hline \multicolumn{3}{|l|}{ Battery: } \\
\hline Type & Li-battery & Li-battery \\
\hline Capacity & $720 \mathrm{Wh}(24 \mathrm{~V} / 30 \mathrm{Ah})$ & $720 \mathrm{Wh}(24 \mathrm{~V} / 30 \mathrm{Ah})$ \\
\hline \multicolumn{3}{|l|}{ Load : } \\
\hline Application & $\begin{array}{l}\text { Cooling and lighting of a low- } \\
\text { energy house (ZEH-2) used } \\
\text { as a meeting room }\end{array}$ & $\begin{array}{l}\text { lighting of stairway from } \\
\text { basement to } 8^{\text {th }} \text { floor of a } \\
\text { building }\end{array}$ \\
\hline Type & $\begin{array}{l}\text { split inverter-type air } \\
\text { conditioner (Hitachi RAS- } \\
22 \mathrm{NB} \text { ) and lighting }\end{array}$ & $\begin{array}{l}\text { split inverter-type air } \\
\text { conditioner (Hitachi } \\
\text { RAS-22NB) and lighting }\end{array}$ \\
\hline Load power & $\begin{array}{l}\text { 100 700W (air conditioning) } \\
\text { and 100W(LED lighting) }\end{array}$ & $150-250 \mathrm{~W}$ \\
\hline Energy demand & 6 8 kWh/day (not every day) & 3.6 6 kWh/day \\
\hline Load pattern & Mostly in daytime & 24 hours a day \\
\hline \multicolumn{3}{|l|}{ Inverter: } \\
\hline Maximum output & $1.5 \mathrm{~kW} / 220 \mathrm{~V}$ & $300 \mathrm{~W} / 220 \mathrm{~V}$ \\
\hline
\end{tabular}

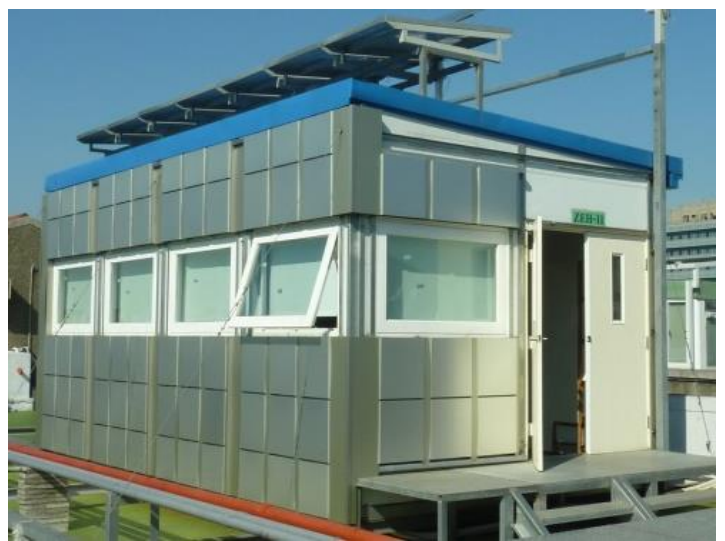

Fig. 6. Low-energy house (ZEH-2).
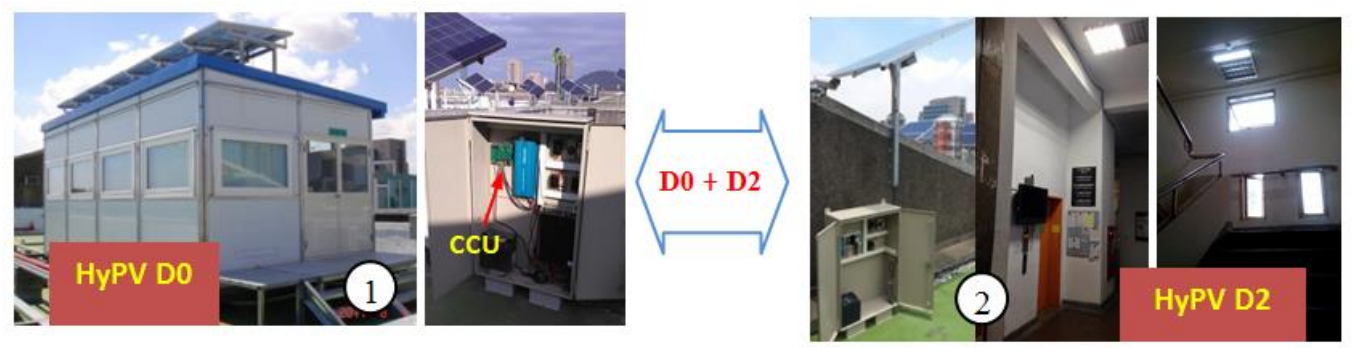

Fig. 7. Binary connection of two HyPVs - Hynet-2A.

A Li-battery with storage capacity $720 \mathrm{Wh}(24 \mathrm{~V} / 30 \mathrm{Ah})$ was used. A microprocessor-based controller 
(MCU) was installed. MCU performs ATS switching between PV and grid modes automatically using a switching scheme [8] and carries out CV (constant-voltage) control for battery overcharge protection and system protection, etc. For safety reason, mechanical ATS was used. The battery, inverter, switches, surge protection device, and controller (MCU) are all mounted inside a ventilated chassis.

HyPV-D2 is a solar PV system for LED lighting in the stairways of a building in National Taiwan University, from basement to $8^{\text {th }}$ floor. $490 \mathrm{Wp}$ solar PV module was installed with battery capacity 720 Wh. The power consumption of LED lighting varies between $150-250 \mathrm{~W}, 24 \mathrm{~h}$ per day.

The outlook of Hynet-2A is shown in Fig. 7. The EMS (energy management system) of Hynet-2A is shown in Fig. 8.

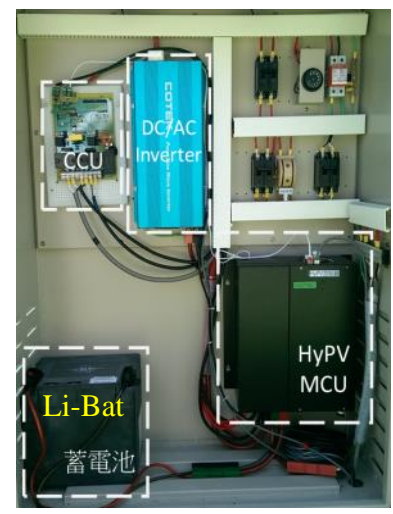

Fig. 8. EMS (energy manage system) of Hynet-2A.

\subsection{Control logic of Hynet-2A}

The two HyPVs are connected through a CCU as shown in Fig. 9. The control logic consists of three states, described as follows:

State I: Searching the donor system for PV energy sharing

(1) Measure battery voltages of D0 and D2

(2) Choose the HyPV with full-charge voltage $\mathrm{V}_{\mathrm{H}}$ as the donor and the other as the receptor.

State II: Starting PV sharing (R1 ON)

(1) When battery voltage of the receptor is $\left\langle\mathrm{V}_{\mathrm{Hr}^{-}}-\mathrm{dV}\right.$, relay R1 is activated and PV sharing is started. $\mathrm{V}_{\mathrm{Hr}}$ is the high voltage limit of receptor battery, $\mathrm{dV}_{\mathrm{r}}$ is the voltage margin of the receptor battery.

(2) The battery discharge energy $E_{d}$ in the donor is measured right after the start of PV sharing.

State III: Stopping PV sharing (R1 OFF)

(1) When the donor battery discharged energy $E_{d}$ reached an amount $\mathrm{S}_{\mathrm{D}}$, the PV sharing operation is terminated.

(2) The system returns to State I.

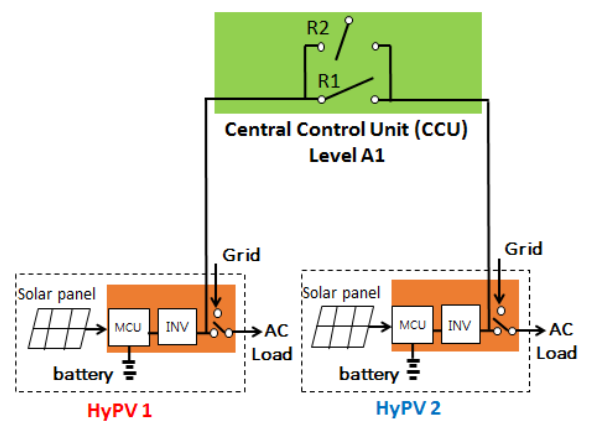

Fig. 9. Binary connection of two HyPVs through CCU. 


\subsection{Test results}

The test result in a partly-cloudy day is shown in Fig. 10 and Fig. 11, for variations of battery voltage, PV power generation, load power, and PV sharing control. The total time duration for PV sharing is 249 minutes with total PV energy sharing $840 \mathrm{Wh}$ from D0 to D2. The increase in PV energy generation of D0 due to PV sharing with D2 is $43 \%$. Table 2 shows the daily performance of Hynet-A2.

Hynet-2A was continuously run to collect long-term performance data. Fig. 12 shows the daily PV sharing time and energy supply of D0 for 2 months. The average PV sharing time is 68 minutes per day and the increase in PV energy generation of D0 due to PV sharing with D2 is $17 \%$.

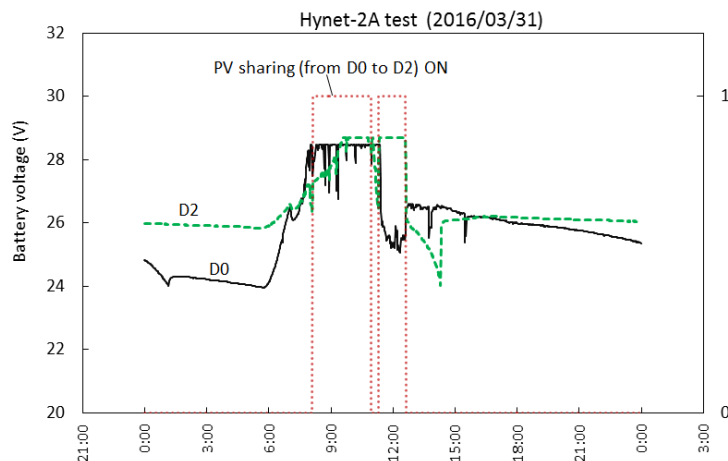

(a)

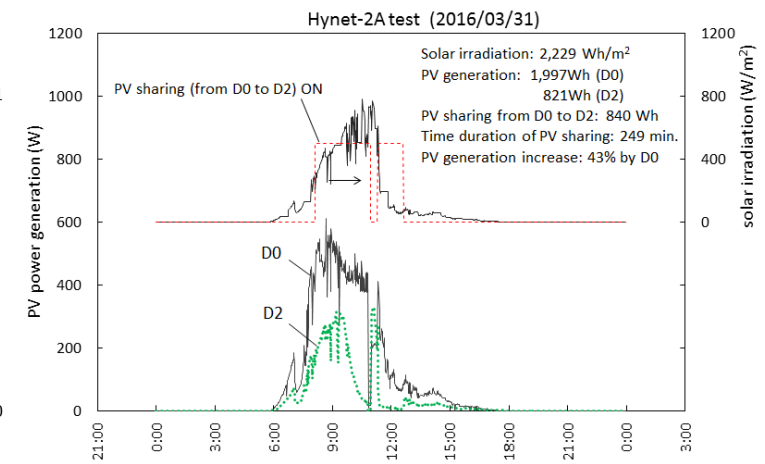

(b)

Fig. 10. Daily performance of Hynet-2A: (a)voltage variation; (b)PV power generation.

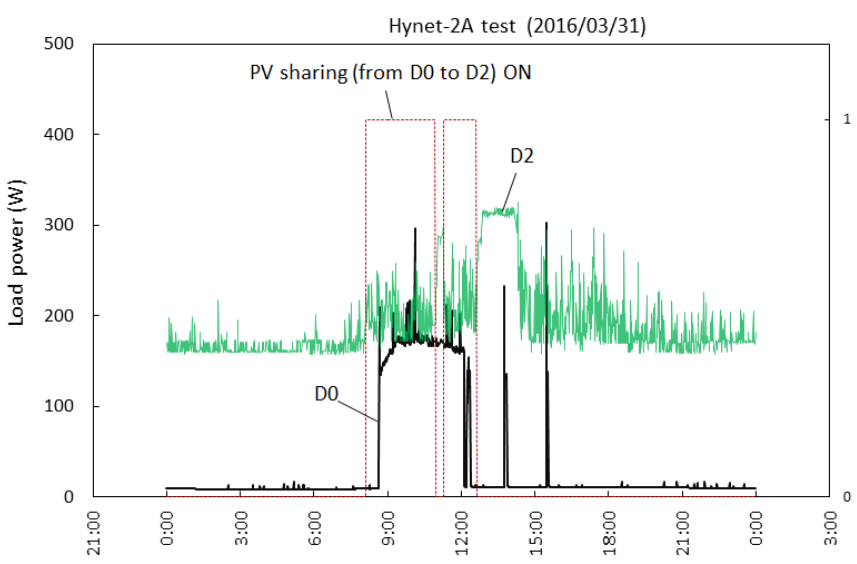

Fig. 11. Load power variation of Hynet-2A.

Table 2. Daily performance of Hynet-2A

\begin{tabular}{lrr}
\hline \multicolumn{1}{c}{ 2016/3/31 } & HyPV-D0 & HyPV-D2 \\
\hline Solar PV energy generation, Wh/day & 1,997 & 821 \\
Battery charge, Wh/day & 667 & 642 \\
Inverter output energy (PV mode), Wh/day & 1,846 & 625 \\
Energy output to neighbour (PV energy sharing), Wh/day & 840 & - \\
Load energy consumption, Wh/day & 846 & 4,628 \\
Energy supply from grid (grid mode), Wh/day & 82 & 3,260 \\
Increase of PV energy generation due to sharing, Wh/day & $600(+43 \%)$ & - \\
\hline
\end{tabular}



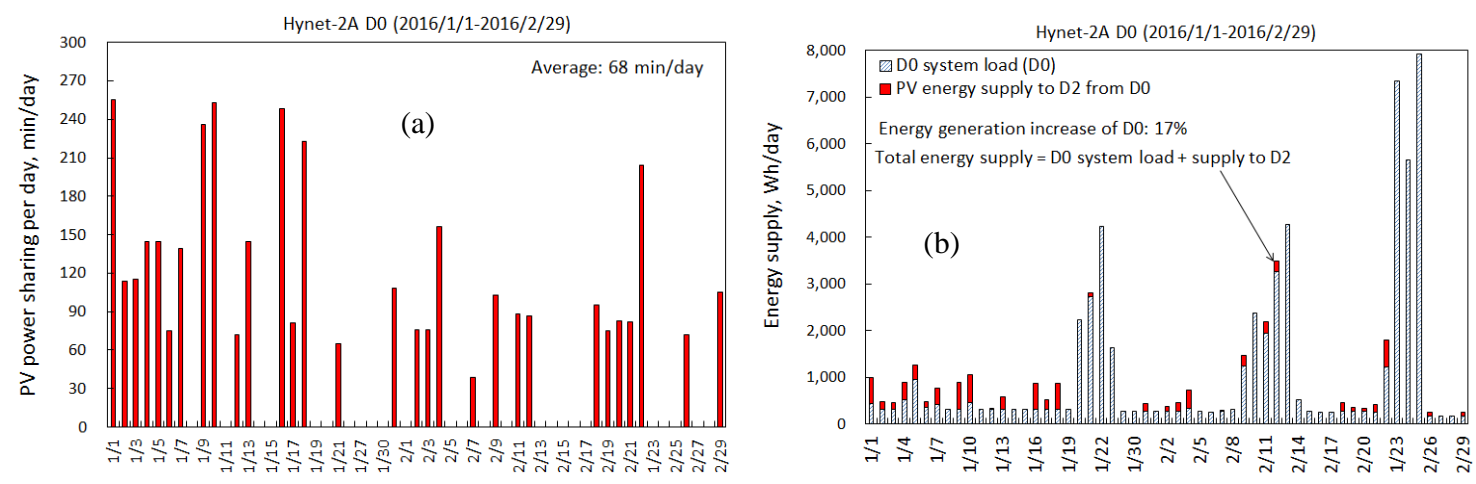

Fig. 12. Daily PV sharing time (a) and energy supply of D0 (b).

Since the MCU controller was tuned (March 18) and the battery of D0 was changed to 100Ah/48V LA battery (April 10) during the long-term test, the daily PV energy generation per $\mathrm{kWp}$ installation varies. Fig. 13 shows that it continues to increase and finally reaches $2.29 \mathrm{kWh} / \mathrm{kWp}$ per day for D0 and 2.97 for D2, both approaches the mean value (2.47) of grid-tied FIT PV systems in Taipei area. The average PV sharing operation is 332 minutes per day.

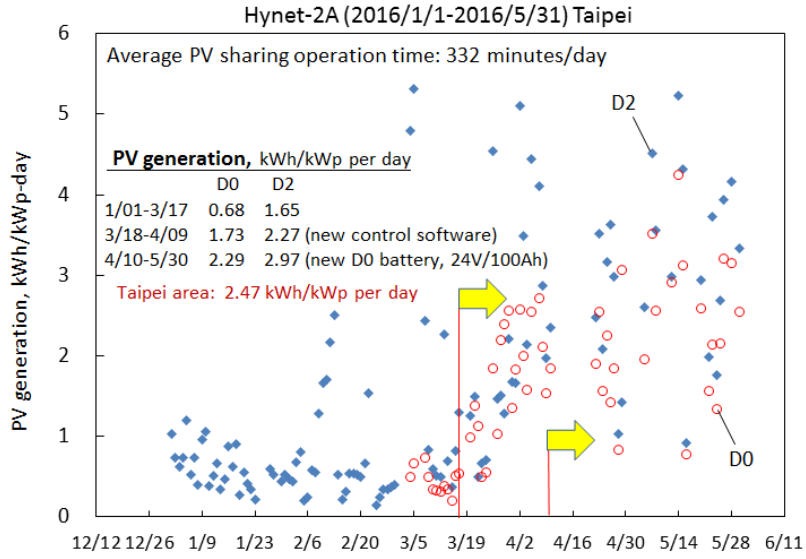

Fig. 13. Long-term test of Hynet-2A.

Fig. 14 shows the long-term performance of D2 for 8 months. It is seen that the average PV energy generation is $2.92 \mathrm{kWh}$ /day per $\mathrm{kWp} \mathrm{PV}$ installation, which is higher than the mean value (2.47) of gridtied FIT solar PV systems installed in Taipei area. 23.5\% of PV-mode energy supply in D2 is from D0.

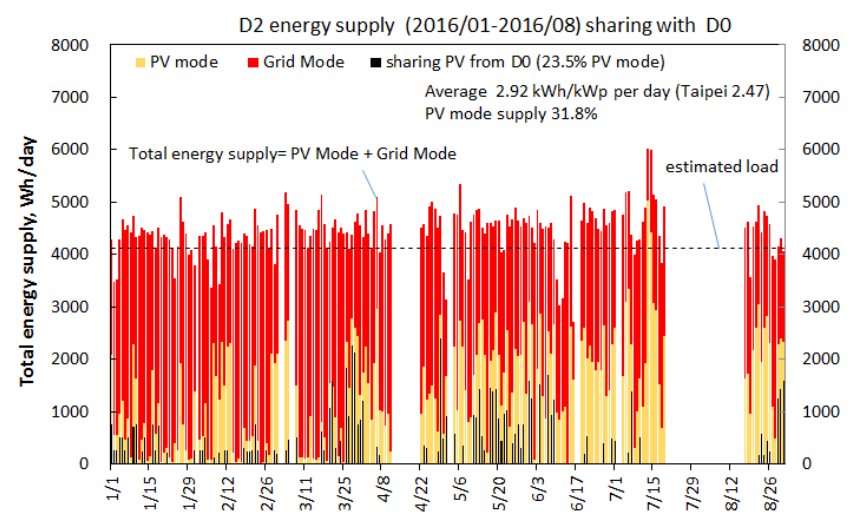

Fig. 14. Performance of D2 with PV sharing. 


\section{Conclusion}

The hybrid PV system (HyPV) [8] operates at stand-alone PV mode or grid mode automatically and does not feed PV power into grid. HyPV operates at PV mode when solar radiation or battery energy is high enough. It switches to grid mode when battery storage is low. There may be a PV generation loss if the system match between load power and size of battery and PV module is not proper.

To cope with this problem, we proposed a networking technique, called "solar pyramid micro-grid", which connects neighbor HyPVs level by level, and shares solar PV power each other through a switching control. The binary connection of HyPVs is the simplest design to build a solar pyramid micro-grid. Solar PV power generation of eight HyPVs can be shared each other. A smart solar micro-grid can be built based on the concept of pyramid solar micro-grid.

In the present study, the binary connection of two HyPV systems connected at A-level was investigated experimentally. The test results show that the sharing of solar PV power each other can effectively increase the PV power generation of the whole system.

\section{Acknowledgment}

This study was supported by National Energy Program II, MOST 103-3113-E-002-006 made by Ministry of Science and Technology, Taiwan.

\section{References}

[1] Harry Wirth, Recent Facts about Photovoltaics in Germany. Fraunhofer Institute for Solar Energy Systems ISE, January 7 , 2015.

[2] Pudjianto D, Djapic P, Dragovic J, Strbac G. Grid Integration Cost of Photovoltaic Power Generation-Direct Costs Analysis related to Grid Impacts of Photovoltaics. Imperial College London, September 2013. Published by Intelligent Energy Europe; 2013.

[3] Thim F, Rothert M, Kever F. Where is the optimum? Comparison of system topologies for small PV hybrid systems. In: Proc of $7^{\text {th }}$ Int. PV-Hybrid and Mini-Grid Conference, Bad Hersfeld, Germany; Apr 10-11, 2014.

[4] Liu X, Wang P, Loh PC. A hybrid AC/DC micro-grid and its coordination control. IEEE Transactions on Smart Grid, 2011; 2(2):278-286.

[5] Carmeli MS, Castelli-Dezza F, Mauri M, Marchegiani G, Rosati D. Control strategies and configurations of hybrid distributed generation systems. Renewable Energy, 2012; 41:294-305.

[6] Smart grid in GuangTsai, Pingtung, [Online]. Taiwan. Available: http://www.pthg.gov.tw/guangtsai/cp.aspx?n=37C252FE8051F769

[7] Sintamarean N, Blaabjerg F, Wang H, Iannuzzo F, Rimmen P. Reliability oriented design tool for the new generation of grid connected PV-Inverters. IEEE Transactions on Power Electronics, 2015; 30(5):2635-2644.

[8] Hsu PC, Huang BJ, Lin WC, Chang YJ, Chang CJ, Li K, Lee KY. Effect of switching scheme on the performance of a hybrid solar PV system. Renewable Energy, 2016; 96:520-530. 